\title{
Statistical Model Estimates Potential Yields in Pear Cultivars 'Blanquilla' and 'Conference' before Bloom
}

\author{
Carlos Miranda Jiménez and J. Bernardo Royo Díaz \\ Departamento de Producción Agraria, Universidad Pública de Navarra. Campus de Arrosadía 31006 \\ Pamplona, España
}

ADDITIONAL INDEX WORDS. Pyrus communis, fruit set, average fruit weight, yield efficiency, trunk cross-sectional area, flower density

\begin{abstract}
Spring frosts are usual in many of Spain's fruit-growing areas, so it is common to insure crops against frost damage. After a frost, crop loss must be evaluated, by comparing what crop is left with the amount that would have been obtained under normal conditions. Potential crop must be evaluated quickly through the use of measurements obtainable at the beginning of the tree's growth cycle. During 1996 and 1997 and in 95 commercial plots of 'Blanquilla' and 'Conference' pear (Pyrus communis L.), the following measurements were obtained: trunk cross-sectional area (TCA, $\left.\mathrm{cm}^{2}\right)$, space allocated per tree $\left(\mathrm{ST}, \mathrm{m}^{2}\right)$, trunk cross-sectional area per hectare (TCA/ha), flower density (FD, number of flower buds/cm² TCA), flower density per land area (FA, number of flower buds/ $\mathbf{m}^{2}$ land area), cluster set (CS, number of fruit clusters/ number of flower clusters, \%), crop density (CD, number of fruit/cm ${ }^{2}$ TCA), fruit clusters per trunk cross-sectional area

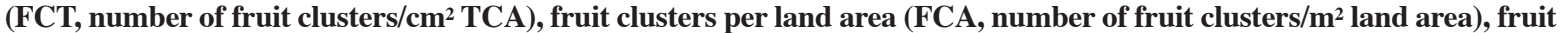
number per cluster (FNC), average fruit weight (FW, g), average yield per fruit cluster (CY, g), yield efficiency (YE, fruit $\mathrm{g} \cdot \mathrm{cm}^{-2}$ TCA), and tree yield (Y, fruit $\mathrm{kg} /$ tree). CS and average CY were related to the rest of the variables through the use of multiple regression models. The models that provided the best fit were $\mathrm{CS}=\mathrm{TCA} / \mathrm{ha}-\mathrm{FA}$ and $\mathrm{CY}=-\mathrm{FA}-\mathrm{FCT}$. These models were significant, consistent, and appropriate for both years. Predicted yield per land area was obtained by multiplying FA $\times$ CS $\times$ CY. The models' predictive ability was evaluated for 46 different plots in 2001 and 2002 . Statistical analysis showed the models to be valid for the forecast of orchards' potential yield efficiency, so that they represent a useful tool for early crop prediction and evaluation of losses due to late frosts.
\end{abstract}

Spring frosts are usual in many of Spain's fruit-growing areas, so it is common to insure crops against frost damage. Frosts affect mainly flowers or young developing fruit, so that any damage must be estimated comparing the amount of fruit left on the tree to the number that would have been produced under normal conditions. Insurance technicians face two main difficulties in their work: the study must be performed after the frost has occurred (that is, must be performed using variables which can be measured at that point) and it must be performed in the field, quickly and without complex equipment.

Tree yield is a function of the number of both fruit on the tree and their weight. The number of fruit depends on the flower density (number of flower clusters per trunk cross-sectional area (TCA) (Lombard et al, 1988), the tree's size and percentage of set. The percentage of fruit set decreases as the flower density increases, but this relationship is heavily influenced by climate (Chang et al., 1987; Dennis, 1986). When fruit set is too large for the tree's size, it becomes necessary to thin to ensure that the remaining fruit reach commercial size (Costa and Vizzotto, 2000).

Typical fruit size is different for each cultivar (Faust, 1989), although it is also highly dependent on the number of fruit left on the tree (Chang et al., 1987; Gu and Lombard, 1994; Miranda and Royo, 2003), climate (Lakso et al., 1995, Warrington et al., 1999) and cultural techniques (Berman and DeJong, 1996; Naor et al., 2000). Fruit growth rate is faster for early cultivars but, since growth time is shorter, final size tends to be smaller (Carrera, 1999, Faust, 1989).

Only tree size, plantation density and number of flower buds after pruning are available at the beginning of the active period to estimate potential yield in a simple, rapid way. Potential yield increases with tree size, although not linearly since bigger trees are less efficient (Barritt et al., 1997; Faust, 1989; Robinson et

Received for publication 15 Jan. 2003 . Accepted for publication 28 Feb. 2003 We thank Richard Marini for his review and statistical advice. This study was financed by Agroseguro S.A.,Agrupación Española de Entidades Aseguradoras de los Seguros Agrarios Combinados S.A. C/Gobelas 23, 28023 Madrid, España. al., 1991). Many studies have shown that tree size and TCA are closely related, so that TCA is used regularly to compare different plots'vigor(TCA/ha), efficiency ( $\mathrm{kg} / \mathrm{TCA}$ ), flower load (number of flowers/TCA), etc. (Barritt et al., 1997; Carusso et al., 1999; Dennis et al., 1996; Lombard et al., 1988; Strong and Azarenko, 2000; Westwood and Roberts, 1970). Plant density also influences yield, since it affects the amount of light received by the trees. Robinson and Lakso (1991) found that the amount of light intercepted by a tree had a direct correlation with TCA per available area (TCA/ha), and Miranda and Royo (2003) found that TCA/ha was a good parameter to estimate peach and nectarine potential yields.

The bud load after pruning is another one of the main factors in a fruit tree's productivity (Chang et al., 1987; Kappel, 1990; Lombard etal., 1988). Some pomologists have proposed flower bud density (number of flower buds per TCA) as an index to express the magnitude of flowering (Lombard et al, 1988). Royo and Miranda (2002) found in apple that cluster set was related to flower density per land area (number of flower buds $/ \mathrm{m}^{2}$ ).

The purpose of this study was the development of a mathematical model, using parameters which can be easily measured at the beginning of the active period, to estimate potential yield for 'Blanquilla' and 'Conference' pear (Pyrus communis L.), the main cultivars grown in Spain (Prognosfruit, 1999).

\section{Materials and Methods}

Data Collection. Data were collected during 1996 and 1997 in fully producing commercial plots, with trees ranging between 6 and 16 years of age. Orchards were located in the Ebro River Valley, in the provinces of La Rioja, Navarra, Zaragoza and Lérida in Spain. In total, 95 plots were included in the study, out of which 50 were of 'Blanquilla' and 45 of 'Conference'. The plots represented a wide range of growth conditions. Means, standard deviations, minimum and maximum values are shown for cropping characteristics of each cultivar (Table 1). Cultural practices were carried out 
Table 1. Mean \pm standard deviation, and maximum (max) and minimum (min) values for the main agronomic characteristics of the orchards sampled. Data for 1996 and 1997 are pooled.

\begin{tabular}{|c|c|c|c|c|c|c|}
\hline \multirow[b]{2}{*}{ Characteristic } & \multicolumn{3}{|c|}{ 'Blanquilla' } & \multicolumn{3}{|c|}{ 'Conference' } \\
\hline & Mean \pm SD & Min & $\overline{M a x}$ & Mean \pm SD & Min & Max \\
\hline No. of orchards sampled & & 50 & & & 45 & \\
\hline Trunk cross-sectional area (TCA, $\left.\mathrm{cm}^{2}\right)$ & $203.2 \pm 126.7$ & 55.9 & 535.0 & $99.9 \pm 37.5$ & 28.6 & 193.0 \\
\hline Trunk cross-sectional area per hectare $\left(\mathrm{TCA} / \mathrm{m}^{2} \cdot \mathrm{ha}^{-1}\right)$ & $13.1 \pm 6.4$ & 4.2 & 28.1 & $13.6 \pm 4.6$ & 6.6 & 23.5 \\
\hline Space allocated per tree $\left(\mathrm{ST}, \mathrm{m}^{2} /\right.$ tree $)$ & $20.0 \pm 14.3$ & 3.7 & 41.2 & $7.5 \pm 1.5$ & 3.7 & 8.4 \\
\hline Flower density (FD, no. flower buds/ $\left.\mathrm{cm}^{2} \mathrm{TCA}\right)$ & $5.8 \pm 5.0$ & 0.2 & 19.3 & $2.5 \pm 1.6$ & 0.8 & 8.0 \\
\hline Flower density per land area (FA, no. flower buds $/ \mathrm{m}^{2}$ ) & $63.6 \pm 49.3$ & 1.8 & 173.2 & $41.7 \pm 25.0$ & 13.9 & 123.6 \\
\hline Cluster set (CS, no. fruit clusters/100 flower clusters, \%) & $41.7 \pm 23.3$ & 9.5 & 92.9 & $47.9 \pm 18.0$ & 12.6 & 94.6 \\
\hline Crop density (CD, no. fruit $\left./ \mathrm{cm}^{2} \mathrm{TCA}\right)$ & $2.3 \pm 1.2$ & 0.3 & 5.4 & $1.5 \pm 0.6$ & 0.8 & 2.8 \\
\hline Fruit clusters per TCA (FCT no. fruit clusters $/ \mathrm{cm}^{2} \mathrm{TCA}$ ) & $1.5 \pm 0.9$ & 0.1 & 3.9 & $1.1 \pm 0.4$ & 0.5 & 2.2 \\
\hline Fruit clusters per land area (FCA, no. fruit clusters $/ \mathrm{m}^{2}$ ) & $17.3 \pm 9.4$ & 1.5 & 34.6 & $17.3 \pm 5.6$ & 8.7 & 34.7 \\
\hline Average fruit number per cluster (FNC) & $1.6 \pm 0.5$ & 1.0 & 3.4 & $1.4 \pm 0.3$ & 1.0 & 2.1 \\
\hline Fruit weight $(\mathrm{FW}, \mathrm{g})$ & $117.6 \pm 27.6$ & 94.0 & 188.4 & $165.0 \pm 22.2$ & 121.0 & 201.0 \\
\hline Cluster yield (CY, g) & $190.1 \pm 76.9$ & 94.0 & 395.3 & $214.0 \pm 59.0$ & 128.6 & 328.8 \\
\hline Yield efficiency (YE, g fruit/cm² TCA) & $239.1 \pm 121.5$ & 43.3 & 525.1 & $227.3 \pm 72.7$ & 101.2 & 554.2 \\
\hline Yield per tree $(\mathrm{kg} /$ tree $)$ & $50.6 \pm 45.5$ & 7.1 & 187.3 & $21.3 \pm 7.6$ & 7.3 & 37.3 \\
\hline Yield per hectare $(\mathrm{T} / \mathrm{ha})$ & $2.8 \pm 1.4$ & 0.5 & 5.7 & $3.0 \pm 1.1$ & 2.0 & 8.0 \\
\hline
\end{tabular}

as is normally done commercially in the area. Hand thinning was performed by the growers between 50 and $80 \mathrm{~d}$ after full bloom (DAFB), with 'Blanquilla' being thinned earlier.

For each plot and year, 20 trees were chosen randomly between winter pruning and bloom. Trunk cross-sections (measure $15 \mathrm{~cm}$ above the graft union), number of flower buds left after pruning on the whole tree, and distance to neighboring trees were measured. Fifty buds were marked in each of the chosen trees, so that all of them were on the same main branch, and that they represented all positions (interior, exterior, upside and downside) and the ratio at which they occurred in the trees.

Harvest maturity was determined by measuring flesh firmness at the greenest part of 100 randomly chosen fruit in the plot, using a Penefel penetrometer(Agro-Technologie, Tarascon, France) with a $0.5-\mathrm{cm}^{2}$ point. Harvest took place when average firmness was 5.5 to $6 \mathrm{~kg} \cdot \mathrm{cm}^{-2}$ for 'Blanquilla' and 6.5 to $7 \mathrm{~kg} \cdot \mathrm{cm}^{-2}$ for 'Conference' (Carrera, 1999), and all fruit on a tree were picked on one day. At that time, number of fruit clusters and number of fruit per cluster were counted, and the largest equatorial size was measured for the fruit on the 50 marked buds per tree. At the same degree of ripeness, 100 fruit were chosen randomly and their largest equatorial size and weight measured. Table 1 reflects all the measurements that were made, and their units. For each plot, the values used in the regression analysis were the averages for all 20 sampled trees.

MoDEL BUILDING.To obtain expected yield for a pear plot, yield was separated into its individual components (cluster set and yield per fruit cluster) and multiple linear regression models linking each with parameters that could be measured at the beginning of the activity cycle were examined. Therefore, two models were evaluated: in the first one CS was the dependent variable and the independent variables were TCA, ST, TCA/ha, FD, FA, and their respective squared terms. In the second model, CY was the dependent variable and the independent variables were TCA, TCA/ha, FD, FA, FCT, FCA, CD, FNC, and their respective squared terms. The relationships were evaluated by fitting polynomial regression models with the Linear Regression Procedure of SPSS (SPSS Inc., Chicago, Ill.) and the Backward Stepwise Elimination Option, as described by Miranda and Royo (2003). The internal validity of the models was tested by coefficient of determination $\left(R^{2}\right)$, mean square error (MSE), the prediction sum of squares (PRESS), and the adjusted coefficient of multiple determination $\left(R_{a}^{2}\right)$, defined by Neter et al. (1996) as the division of each of the sums of squares that constitute the $R^{2}$ by its associated degrees of freedom. Residuals were analyzed to determine the presence of outliers and nonconstant error variance. Variance inflation factor (VIF) for the parameter estimates was calculated to detect intercorrelation between variables. The best models were, for $\mathrm{CS}, \mathrm{CS}=\mathrm{TCA} / \mathrm{ha}$ - FA and, for CY, CY = -FA - FCT. Analysis of covariance was then performed with the GLM Procedure of SPSS (Marini, 1999) to test equality of models for different years. The categorical variable (year) was included as the indicator or dummy variable and the continuous variables for CS model (FA and TCA/ha) and for CY model (FCT and FA), were included as the covariates. Type III sums of squares were used to evaluate the significance of the indicator variable and any interaction terms involving the indicator variable (year $\times$ FA or year $\times \mathrm{TCA} / \mathrm{ha}$, for example). Because year and the interaction terms containing year were not significant $(p>0.05)$, data from all the orchards were pooled to develop two models for each cultivar: one for cluster set estimation and another one for yield per cluster estimation.

Analysis of covariance was also performed to test equality of cluster set models for both cultivars. Cultivar was included as the dummy variable andFAandTCA/ha were included as the covariates. Because cultivar and the interaction terms containing cultivar were not significant $(p>0.05)$, data from all the orchards were pooled to develop one cluster set model for both cultivars.

Model VALIDATION. In order to validate the models obtained, a validation data set was obtained using 21 'Blanquilla' plots and 25 'Conference' plots, different from the previous ones in years 2001 and 2002. Validation data were obtained in the same way as described earlier. Two techniques were used to validate the models:

1) The validation data set was used to produce a validation model by re-estimating the model parameters using the Backward Elimination Option approach to develop the estimation model and the models were compared for consistency.

2) Regression parameter estimates from the estimation models were used to predict outcomes for observations in the validation data set and then the mean squared prediction error(MSPR) was calculated 
Table 2. Statistics and parameter estimates from regression models for fruit set (FS) estimation. The estimation model was developed from 50 'Blanquilla' and 45 'Conference' pear orchards sampled in 1996 and 1997. Validation model was developed from 46 orchards sampled in 2001 and 2002.

\begin{tabular}{lcc}
\hline Statistic or parameter estimate & Estimation model & Validation model \\
\hline Intercept & 52.22 & 53.34 \\
Standard error of intercept & 3.45 & 4.26 \\
Regression coefficient for TCA/haz & 0.94 & 1.20 \\
Standard error for TCA/ha & 0.20 & 0.32 \\
Standardized regression coefficient for TCA/ha & 0.26 & 0.34 \\
Variance inflation factor for TCA/ha & 1.00 & 1.24 \\
Regression coefficient for FAy & -0.40 & -0.48 \\
Standard error for FA & 0.03 & 0.05 \\
Standardized regression coefficient for FA & -0.80 & -0.94 \\
Variance inflation factor for FA & 1.00 & 1.24 \\
Prediction sum of squares (PRESS) & 13146.63 & \\
Error sum of squares (SSE) & 12410.13 & 4465.72 \\
Mean squared prediction error (MSPR) & & 105.30 \\
Mean square error (MSE) & 130.63 & 103.85 \\
$P>$ F & $<0.0001$ & $<0.0001$ \\
Coefficient of multiple determination $R^{2}$ & 0.69 & 0.71 \\
Adjusted coefficient of multiple determination $R_{\mathrm{a}}^{2}$ & 0.68 & 0.70 \\
Total DF & 94 & 45 \\
\hline
\end{tabular}

zTCA/ha $=$ trunk cross-sectional area per hectare $\left(\mathrm{m}^{2} \cdot \mathrm{ha}^{-1}\right)$.

$\mathrm{yFA}=$ flower density per land area (no. flower clusters $/ \mathrm{m}^{2}$ land area).

and compared with the mean square error (MSE) of the regression fit to the model-building data set (Neter et al., 1996).

Graphical procedures (Bland and Altman, 1986) were used to compare the predicted yield to the observed yield (OYA) for each orchard. Predicted yield per land area (PYA) was obtained by multiplying FA $\times \mathrm{CY} \times \mathrm{CS}$. Scatter plots of values for the predicted against the true yields are presented. GLM Procedure of SPSS was used to evaluate the linear relationship for OYAand PYA. Values for

PYA were substracted from OYA for each orchard, and differences were plotted against the OYA for an orchard. Lack of agreement was evaluated by calculating the relative bias, estimated by the mean of the differences (d) and the standard deviation (SD) of the differences. Normality was visually evaluated with a frequency distribution of individual differences. Examine Procedure of SPSS was used to obtain a Wilkes-Shapiro W statistic as a formal test for normality (Marini, 2001).

Table 3. Statistics and parameter estimates from regression models for cluster yield (CY,g) estimation. The estimation models were developed from 50 'Blanquilla' and 45 'Conference' pear orchards sampled in 1996, and 1997. Validation models were developed from 21 'Blanquilla' and 25 'Conference' orchards sampled in 2001 and 2002.

\begin{tabular}{|c|c|c|c|c|}
\hline \multirow[b]{2}{*}{ Statistic or parameter estimate } & \multicolumn{2}{|c|}{ 'Blanquilla' } & \multicolumn{2}{|c|}{ 'Conference' } \\
\hline & Estimation model & Validation model & Estimation model & Validation model \\
\hline Intercept & 305.29 & 329.15 & 319.54 & 341.70 \\
\hline Standard error of intercept & 11.96 & 17.78 & 15.18 & 18.01 \\
\hline Regression coefficient for $\mathrm{FA}^{\mathrm{z}}$ & -0.82 & -0.92 & -1.60 & -1.44 \\
\hline Standard error for FA & 0.13 & 0.25 & 0.21 & 0.28 \\
\hline Standardized regression coefficient for FA & -0.52 & -0.47 & -0.71 & -0.64 \\
\hline Variance inflation factor for FA & 1.22 & 1.25 & 1.14 & 1.69 \\
\hline Regression coefficient for FCTy & -41.81 & -49.62 & -35.45 & -49.66 \\
\hline Standard error for FCT & 7.13 & 11.46 & 13.45 & 18.65 \\
\hline Standardized regression coefficient for FCT & -0.49 & -0.56 & -0.24 & -0.33 \\
\hline Variance inflation factor for FCT & 1.22 & 1.25 & 1.14 & 1.69 \\
\hline Prediction sum of squares (PRESS) & 89296.43 & & 57933.73 & \\
\hline Error sum of squares (SSE) & 78336.85 & 39634.59 & 48739.49 & 16819.07 \\
\hline Mean squared prediction error (MSPR) & & 2077.29 & & 830.80 \\
\hline Mean square error (MSE) & 1666.74 & 2201.92 & 1107.72 & 764.50 \\
\hline $\mathrm{P}>\mathrm{F}$ & $<0.0001$ & $<0.0001$ & $<0.0001$ & $<0.0001$ \\
\hline Coefficient of multiple determination $R^{2}$ & 0.73 & 0.76 & 0.68 & 0.79 \\
\hline Adjusted coefficient of multiple determination $R_{\mathrm{a}}^{2}$ & 0.72 & 0.74 & 0.66 & 0.78 \\
\hline Total DF & 49 & 20 & 44 & 24 \\
\hline
\end{tabular}

${ }^{\mathrm{z} F A}=$ flower density per land area (no. flower clusters $/ \mathrm{m}^{2}$ land area).

yFCT $=$ fruit clusters per TCA (no. fruit clusters $/ \mathrm{cm}^{2} \mathrm{TCA}$ ). 


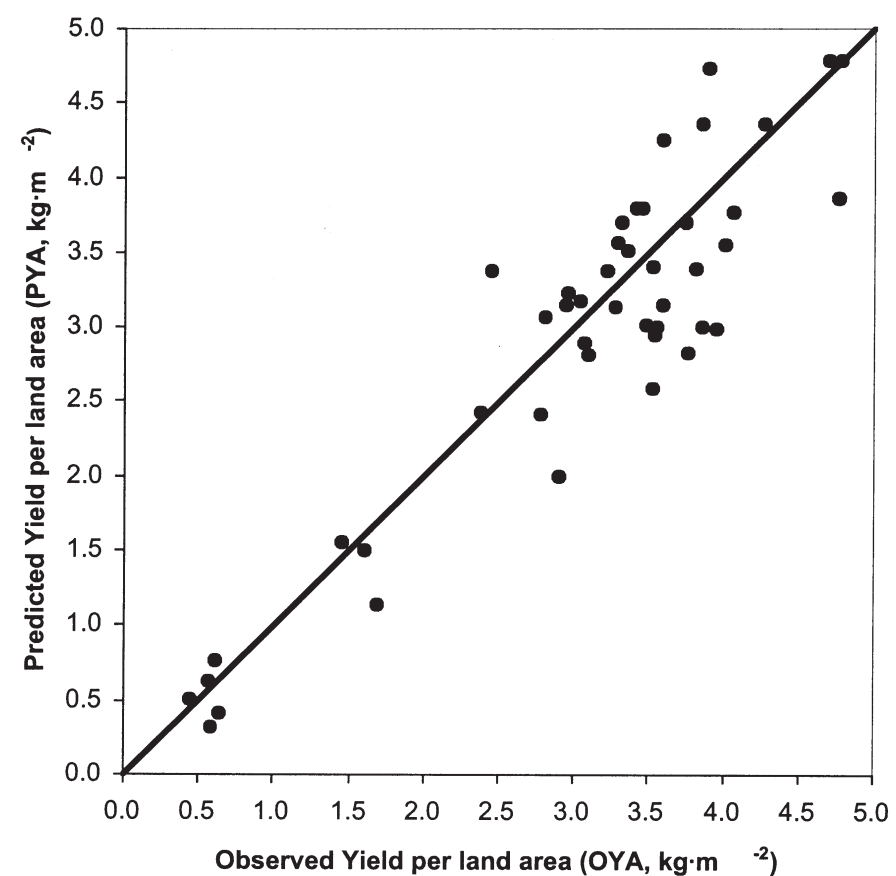

Fig. 1. Plot of predicted yield per land area (PYA), estimated from multiplying $\mathrm{FA} \times \mathrm{CS} \times \mathrm{CY}$ (see Table 1 for definitions) vs. the observed yield per land area (OYA) for each orchard in the validation data set. Along with estimated PYA for each orchard is the line of equality on which all points would lie if the estimation method gave the true value for every orchard.

\section{Results}

Parameter estimates and statistics obtained from SPSS output are presented for the estimation and validation models developed for cluster set (Table 2) and yield per cluster (Table 3). Parameter estimates, $R^{2}$, and $R_{a}{ }^{2}$ values are similar for the estimation and validation models, providing some assurance about the applicability of the model to data beyond those on which the model is based (Neter et al., 1996). The VIF for all parameter estimates in the estimation models were far below the value of 10 considered as an indicator of the presence of correlation (Neter et al, 1996). Therefore the coefficients obtained are uncorrelated and reliable, and the standardized regression coefficients (the regression coefficients divided by their respective standard deviations) can be used as a valid indicator of the relative influence of each parameter on the dependent variable (Neter et al, 1996).

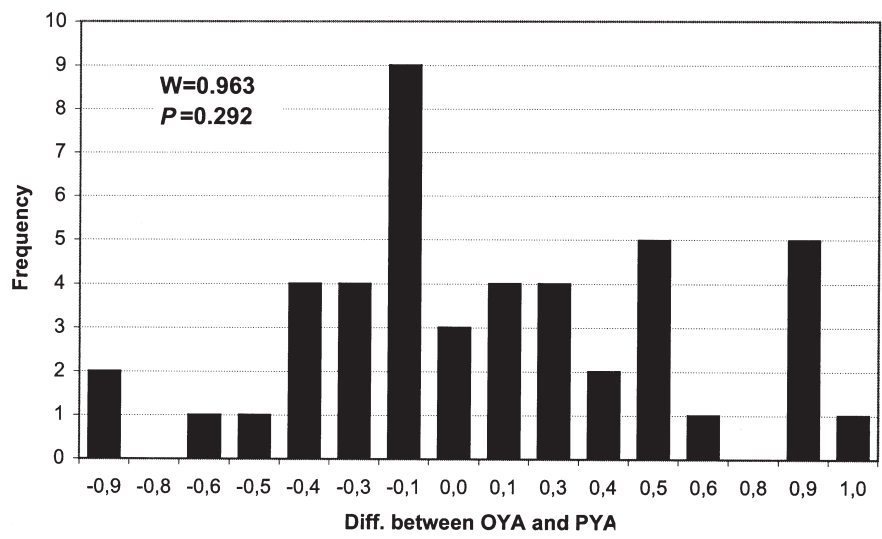

Fig. 3. Frequency plot of the differences plotted in Fig. 2A. Also presented are coefficient and $P$ value for Wilkes Shapiro $\mathrm{W}$ test where the null hypothesis is that the differences come from a normal distribution.
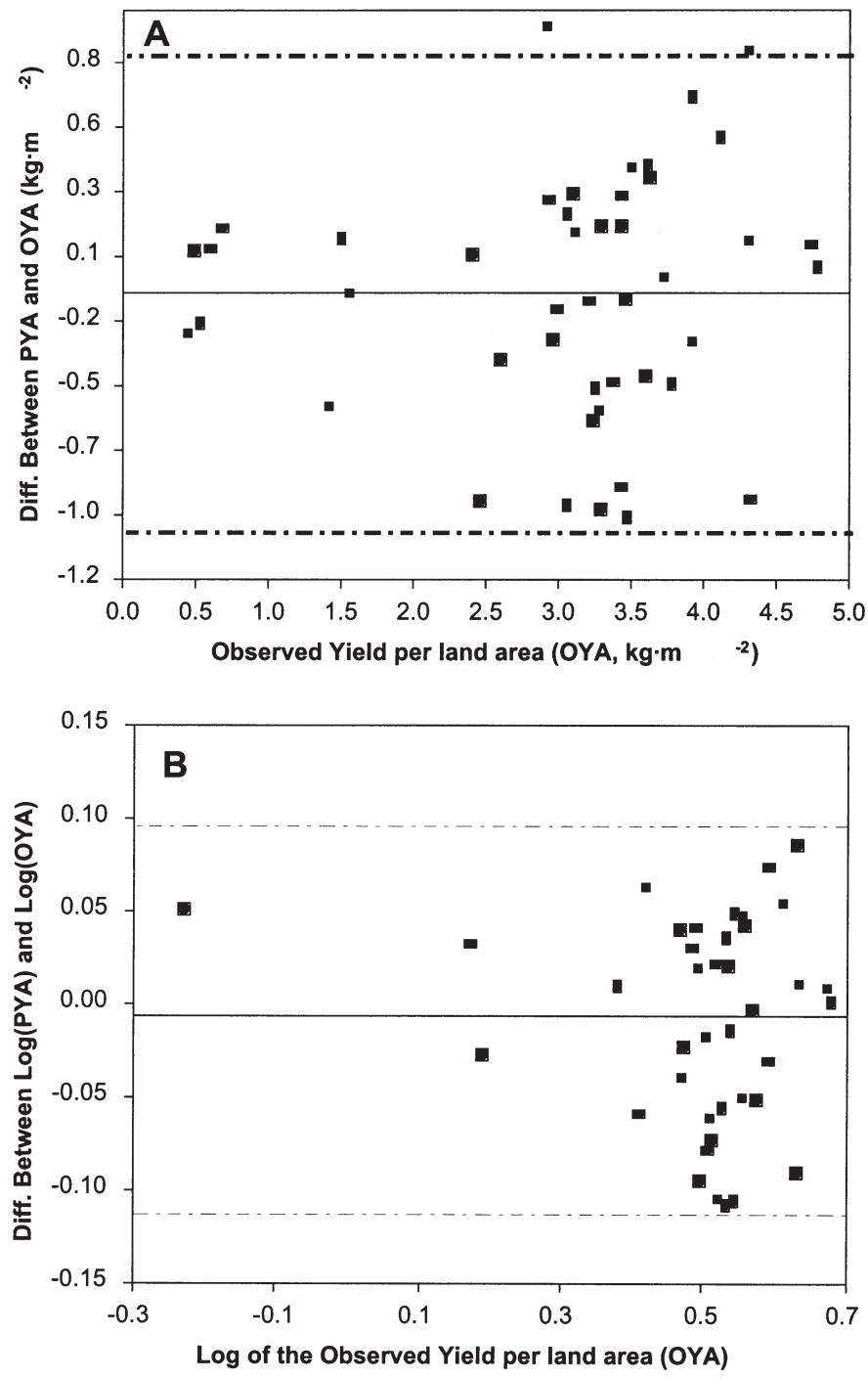

Fig. 2. (A) The difference between predicted yield per land area, estimated from multiplying FA $\times \mathrm{CS} \times \mathrm{CY}$ (see Table 1 for definitions) vs. the observed yield per land area (OYA) for each orchard in the validation data set. (B) The difference between $\log (\mathrm{PYA})$ and $\log (\mathrm{OYA})$ vs. the $\log (\mathrm{OYA})$ for each orchard in the validation data set. The solid line is the mean of the differences. The broken lines are the limits of agreement, calculated as $\mathrm{d} \pm 2 \mathrm{SD}$; where $\mathrm{d}=$ the mean of the differences and $\mathrm{SD}=$ the standard deviation of the differences. If the differences are normally distributed, $95 \%$ of the differences in a population will lie between the limits of agreement.

For the cluster set model (Table 2), FA had the greatest impact (standardized coefficient of -0.80 ), greater than TCA/ha (standardized coefficient $=0.26)$. For the yield per cluster model (Table 3$)$, FA was the most influential factor for both cultivars $(-0.52$ and -0.71 for 'Blanquilla' and 'Conference', respectively), whereas FCT had less influence $(-0.49$ and -0.24 for 'Blanquilla' and 'Conference', respectively).

A means of measuring the actual predictive capability of the models is to use them to predict each case in the validation data set and then to calculate the mean of the squared prediction errors, MSPR. If the MSPR is fairly close to the MSE based on the regression fit to the estimation data set, then the MSE for the selected regression model is not seriously biased and gives an appropriate indication of the predictive ability of the model. In this case, the MSPR from the validation data set for the cluster set model (105.3) differs $\approx 20 \%$ from the MSE of the estimation data set (130.6). The 
same case was true for both yield per cluster models (for 'Blanquilla', MSPR $=2077, \mathrm{MSE}=1667$; and for 'Conference', $\mathrm{MSPR}=831$, MSE $=1108$ ). This implies that the MSE based on the estimation data set is a reasonably valid indicator of the predictive ability of the estimation regression model (Neter et al., 1996).

PRESS criterion is a measure of how well the use of the fitted values for a subset model can predict the observed values of the response value $\mathrm{Y}_{\mathrm{i}}$. The error sum of squares (SSE) is another such measurement. PRESS was calculated for the models developed for cluster set and yield per cluster by summing the squared prediction errors (the difference between the observed and predicted values when one observation is deleted). Some evidence of the internal validity of the fitted model is to compare PRESS and SSE (Miranda and Royo, 2003). PRESS values are reasonably close to SSE, as for CS model PRESS = 13147, SSE = 12410, for 'Blanquilla' yield per cluster model PRESS $=89296, \mathrm{SSE}=78337$, and for ' $\mathrm{Con}-$ ference' yield per cluster model PRESS $=57934, \mathrm{SSE}=48740$, and support the validity of the fitted regression models and of the MSEs as indications of the predictive capability of these models (Neter et al., 1996).

Predicted yield per land area (PYA) was obtained by multiplying $\mathrm{FA} \times \mathrm{CY} \times \mathrm{CS}$. Estimates for PYA were plotted against the true values (OYA) and plot contains a line of equality on which all points would lie if the estimation methods gave exactly the same value as the true value (Fig.1). Data for yield tend to be clustered fairly close to the line. Correlation coefficients were calculated for the plot to test the null hypothesis that the values for the estimation method are not linearly related to the true values. Values obtained from the estimation methods were linearly related to the true values $(r=0.916 P<0.0001)$. However, correlation is an inappropriate analysis for the agreement of the method to the real values, and a plot of the difference between the method against the true values may be more informative (Bland and Altman, 1986; Marini, 2001). Plotting differences against the true value also allow investigation of possible relationships between measurement error and the true values. Lack of agreement between an estimation method and the true value can be evaluated by calculating the bias, estimated by the mean of the differences (d) and the SD of the differences. In Fig. 2 a solid line represents the mean of the differences. If the differences are normally distributed, $95 \%$ of the differences will lie between $d \pm 2 \mathrm{SD}$. These values are referred to as the limits of agreement (Bland and Altman, 1986). The frequency distribution and the $\mathrm{W}$ statistic for the plot of the differences indicate that the data adequately approximate Normality for parametric test to be valid (Fig. 3) (Marini, 2001)

The plot in Fig. 2A indicate that the differences increases as the OYA increases. We could ignore this, but the limits of agreement would be wider apart than necessary for small OYA and narrower than they should be for large OYA. If the differences are proportional to the mean, a logarithmic transformation should yield a better agreement (Bland and Altman, 1986). Fig 2B shows the log-transformed data of fig 2A. This shows there is no apparent relationship between $\log (\mathrm{OYA})$ and the differences. The mean difference is 0.009 and the limits of agreement are -0.112 and 0.095 . However, although there is only negligible bias, the limits of agreement have somehow related to the original scale of measurement. If we take the antilogs of these limits (Bland and Altman, 1986), we get 0.77 and 1.24. However, the antilog of the difference between two values on a $\log$ scale is a dimensionless ratio. The limits tell us that for about the $95 \%$ of cases the PYA will be between 0.77 and 1.24 times. Thus, the PYA may differ from the OYA at most by $\approx 23 \%$. This level of error can be considered acceptable since the purpose of this research was to estimate the yield of pear orchards in a very large area through the use of parameters which can be measured at the beginning of the cycle.

\section{Discussion}

Flower density per land area (FA) had the greatest influence in explaining cluster set, which is supported by previous research (Dennis, 1986, Knight, 1980; Royo and Miranda, 2002; Stover, 2000). Fruit set decreases as the flower density increases, because competition among flowers or developing fruit is stronger (Dennis, 1986). TCA/ha had a minor, though significant, effect in explaining cluster set. This matches the results reported by Miranda and Royo (2003) in peach and Robinson and Lakso (1991) in apple, who determined that TCA/ha is a factor which can be used to explain tree efficiency.

Fruit set also decreases with increasing planting densities or TCA/ha because light distribution is poorer (Robinson and Lakso, 1991) and abscission rate increases. Byers et al (1990) found that artificial shading for 1 or $2 \mathrm{~d}, 30$ to $50 \mathrm{~d}$ after full bloom, had a thinning effect in apple, even higher than chemical thinning. In our results, however, cluster set and TCA/ha were positively related. An explanation for these contradictory results may be that flower density decreases with increasing tree sizes (in the orchards analyzed, $\mathrm{FD}=15.23-1.35 \mathrm{TCA} / \mathrm{ha}+0.03(\mathrm{TCA} / \mathrm{ha})^{2} R^{2}=0.241 P$ $<0.0001, \mathrm{n}=93$ ) and, as previously indicated, fruit set is higher with lower flower densities. The positive effect for lower flower densities counteracts partially the negative effect of lower light interception and, as a result, TCA/ha had a small positive net effect on cluster set.

FA is an index to express bud load, and FCT is an index to express fruit load, and both have proven to be related to the yield per cluster, though FA had the greatest influence in explaining yield per cluster. Higher FA implies more developing fruitlets in the first 7 to 9 weeks, when fruit growth is due to cell division (Faust, 1989), and consequently, a stronger competition between developing fruitlets before the June drop (Dennis, 1986). The negative influence of fruit load on fruit weight has been shown in previous studies $(\mathrm{Gu}$ and Lombard, 1993; Kappel, 1990; Royo and Miranda, 2002; Miranda and Royo, 2003; Robinson et al, 1991).

In this study, predictive models generated with linear regressions analysis indicated that CY and CS could be estimated fairly accurately. Additionally, correlation analyses indicated sample values were correlated with true values. Graphical techniques showed predictive models provided estimated yields that agree with the true yields, though with differences within $\approx 20 \%$ of the true yield. Since the purpose of this research was to estimate the yield of pear orchards in a very large area through the use of parameters which can be measured at the beginning of the cycle, it can be considered valid within reasonable error limits. Thus, the models are valid to forecast crop efficiency, and so provide a useful tool for early forecast of yield and evaluation of crop losses due to late frosts.

The results of this study show that the models developed are good predictors of cluster set and yield per fruit cluster in the Ebro River Valley, so the potential yield of a pear orchard for 'Blanquilla' and 'Conference' can be determined reasonably well from the knowledge of TCA/ha, FCT, and FA.

\section{Literature Cited}

Barritt, B.H, B.S. Konishi, and M.A. Dilley. 1997. Tree size, yield and biennial bearing relationships with 40 apple rootstocks and three scion 
cultivars. Acta Hort. 451:105-112.

Berman, M.E. and T.M. DeJong. 1996. Water stress and crop load effects on fruit fresh and dry weights in peach (Prunus persica). Tree Physiol. 16:859-864.

Bland, J.M. and D.G. Altman. 1986. Statistical methods for assessing agreement between two methods of clinical measurement. Lancet i: 307-310.

Byers, R.E., J.A. Barden, R.F. Polomski, R.W. Young, and D.H. Carbaugh. 1990. Apple thinning by photosynthetic inhibition. J. Amer. Soc. Hort. Sci. 115:14-19.

Carusso, T., P. Inglese, F. Sotile, and F.P. Marra. 1999. Effect of planting system on productivity, dry-matter partitioning and carbohydrate content in above-ground components of 'Flordaprince' peach trees. J Amer. Soc. Hort. Sci. 124:39-45.

Carrera, M. 1999. Variedades y calidad de las peras en Aragón. Asociación Profesional de Empresarios de Productos Hortofrutícolas de la Provincia de Zaragoza, Calatayud. Spain.

Chang, L.S., A.F. Iezzoni, and J.A. Flore. 1987. Yield components in 'Montmorency' and 'Meteor' sour cherry. J. Amer. Soc. Hort. Sci. $112: 247-251$

Costa, G. and G. Vizzotto. 2000. Fruit thinning of peach trees. Plant Growth Regulat. 31:113-119.

Dennis, F.G. 1986. Apple, p1-41. In: S.P. Monselise (ed.). CRC handbook of fruit set and development. 1 ${ }^{\text {st }}$ ed. CRC Press, Boca Raton, Fla.

Dennis, F.G., J.G. Masabni, and D.O. Ketchie. 1996. Evaluating twenty eight strains of 'Delicious' apple in Michigan. J. Amer. Soc. Hort. Sci. 121:988-995.

Faust, M. 1989. Physiology of temperate zone fruit trees. Wiley, N.Y.

$\mathrm{Gu}$, S. and P.B. Lombard. 1994. Effect of crop density on vegetative growth, flowering, fruit size, and yield in 'Nijisseiki' pear trees. Acta Hort. 367:271-277.

Kappel, F. 1990. Yield component analysis of 'Harrow Delight', 'Kieffer', and 'Harvest Queen' pear. J. Amer. Soc. Hort. Sci. 115:25-29.

Knight, J.N. 1980. Fruit thinning of the apple cultivar Cox's Orange Pippin. J. Hort. Sci. 114:852-855.

Lakso, A.N., L. Corelli Grappadelli, J. Barnard, and M.C. Goffinet. 1995. An expolinear model of the growth pattern of the apple fruit. J. Hort. Sci. 70:389-394.

Lombard, P.B., N. Callan, F.G. Dennis, N.E. Looney, N.E. Martin, G.C.
Renquist, and E.A. Mielke. 1988. Towards a standardized nomenclature, procedures, values and units in determining fruit and nut tree yield performance. HortScience 23: 813-817.

Marini, R.P. 1999. Estimating apple diameter from fruit mass measurements to time thinning sprays. HortTechnology 9:109-113.

Marini, R.P. 2001. Estimating mean fruit weight and mean fruit value for apple trees: Comparison of two sampling methods with the true mean. J. Amer. Soc. Hort. Sci. 126:503-510.

Miranda, C. and J.B. Royo. 2003. A statistical model to estimate potential yields in peach before bloom. J. Amer. Soc. Hort. Sci. (in press).

Naor, A., M. Peres, Y. Greenblat, I. Doron, Y. Gal, and R.A. Stern. 2000. Irrigation and crop load interactions in relation to pear yield and fruit size distribution. J. Hort. Sci. Biotech. 75:555-561.

Neter, J., M.H. Kutner, C.J. Nachtshein, and W. Wasserman. 1996. Applied linear regression models. $3^{\text {rd }}$ ed. Irwin, Homewood Ill.

Prognosfruit. 1999. Apple and pear crop forecasts 1999. European Union and other countries. Copa-Cogeca, Eurofru, Fruit-Union Suisse. Belgium.

Robinson, T.L. and A.N. Lakso. 1991. Bases of yield and production efficiency in apple orchard systems. J. Amer. Soc. Hort. Sci. 116 188-194.

Robinson, T.L., A.N. Lakso, and S.G. Carpenter. 1991. Canopy development, yield, and fruit quality of 'Empire' and 'Delicious' apple trees grown in four orchard production systems for ten years. J. Amer. Soc. Hort. Sci. 116:179-187.

Royo, J.B. and C. Miranda. 2002. Evaluación de la cosecha potencial en plantaciones de manzano 'Golden' y 'Gala'. Fruticultura profesional 128:98-103.

Stover, E. 2000. Relationship of flowering intensity and cropping in fruit species. HorTechnology 10:729-732.

Strong, D. and A.N. Azarenko. 2000. Relationship between trunk crosssectional area, harvest index, total tree dry weight and yield components of 'Starkspur Supreme Delicious' apple trees. J. Amer. Pomol. Soc. 54: 22-27.

Warrington, I.J., T.A. Fulton, E.A. Halligan, and H.N. de Silva. 1999.Apple fruit growth and maturity are affected by early season temperatures. J. Amer. Soc. Hort. Sci. 124:468-477.

Westwood, M.N. and A.N. Roberts. 1970. The relationship between trunk cross-sectional area and weight of apple trees. J. Amer. Soc. Hort. Sci. 95:28-30. 